Hospital and Health Services Administration : Principles and Practices by Syed Amin Tabish. First edition, published by Oxford University press New Delhi 2002, pages 959, price Rs 1995/- Hard Bound. ISBN 0195650921.

$\mathrm{M}$ edical Service has made unprecedented progress during the last two decades leading to phenomenal growth in healthcare industry. Healthcare organizations are thus increasingly required to concentrate on evidence based healthcare and cost effective service. This book emphasizes the need to incorporate principles of organizational effectiveness, behavioural sciences and business administration in day to day managerial practices by health care administrators. The book is written exhaustively, single handedly and runs into 8 sections viz. Health planning : past, present and future; Hospital Management : Principles and practice : Managing health care technology; Organizational behaviour; Modern approach to Quality; Healthcare Reforms; Research for health, and Medical Ethics. Though the style of presentation is user friendly and language simple, addition of more schematic diagrams, colour photographs

Robbins Basic Pathology - (2003) by Vinay Kumar, Ramzi S Cotran, Stanley L Robbins, $7^{\text {th }}$ edition. Published by WB Saunders Company, Philadelphia, USA and published in India by Harcourt (India) Pvt Ltd. New Delhi. Pages : 873, Price Rs 750/- ISBN 81-7867-218.

$\mathrm{T}$ The seventh edition of this book of pathology has been extensively revised and almost rewritten in most of the parts. The book has been edited by three well renowned pathologists and various chapters have inputs from 11 authors who are experts in their field. The 2003 edition of the book has well illustrated coloured photographs. The text is beautifully summarized by schematics, flow charts and diagramatic representations of different pathological lesions. This makes it easier to understand and remember the pathophysiology of diseases at molecular and cellular levels. The complicated details have been exhibited in tabulated forms. The and highlighted boxes would have made the subject clear. Dr Tabish's experience of having worked in UK, USA and Middle East has made topics like healthcare in various countries a treat to read. Health care administration related topics have been covered in an innovative manner. Legal aspects of health care in terms of Consumer Protection Act, Labour laws applicable to hospitals, Biomedical Waste Management and Handling rules and Ambulances services have not been handled to the satisfaction and actual requirement of hospital administrators. Hospital management topics are a straight lift from many General management books and lack examples, case studies from hospital field. Overall the book is recommended for healthcare administrators, hospital administration students and as a reference book in medical college libraries.

Contributed by:

Col M Dayananda*, Lt Col SKM Rao ${ }^{+}$

*Professor and Head, ${ }^{+}$Associate Professor, Department of Hospital Administration, Armed Forces Medical College, Pune - 411040. disease mechanism and discussions are complemented by laboratory diagnosis of various disorders.

It is more than five years since the last edition was published. During this period there have been spectacular advances in the field of pathology, such as completion of human genome project and newer knowledge of molecular pathology which have been included in this edition. The book is very useful for all students at undergraduate and postgraduate level and shall be useful for other disciplines of medicine to facilitate the understanding of the pathophysiology of various diseases.

Contributed by:

\section{Col SK Nema}

Professor and Head, Department of Pathology, Armed Forces Medical College, Pune - 411040.

\title{
Events Calendar
}

$15^{\text {th }}-17^{\text {th }}$ October 2004

RSACPCON - 2004

$1^{\text {th }}$ Annual Conference of RSACP

Department of Anaesthesiology

PD Hinduja National Hospital \& Research Centre,
Veer Savarkar Marg, Mahim,

Mumbai - 400016.

Phone : 24451515)

Email : rsacp2004@yahoo.com 